\title{
EM DEFESA DAS TECNOLOGIAS DE INFORMAÇÃO E COMUNICAÇÃO NA EDUCAÇÃO BÁSICA: diálogos em tempos de pandemia
}

\author{
GALDINO RODRIGUES DE SOUSA \\ Universidade Federal de Juiz de Fora (UFJF). Mestre em Educação pela Universidade \\ Federal de Juiz de Fora (UFJF); Doutorando em Educação Física pela Universidade \\ Federal do Espírito Santo (UFES); Professor da Faculdade de Educação da \\ UFJF; Pesquisador vinculado aos grupos EDUCCO; LaboMídia e GEFLIC. \\ ORCID: 0000-0002-1097-738X. E-mail: galdinorodrigues@yahoo.com.br
}

\section{ELIANE MEDEIROS BORGES}

Universidade Federal de Juiz de Fora (UFJF). Doutora em Educação pela Universidade Estadual de Campinas (Unicamp); professora do programa de Pós-graduação em Educação (UFJF); Coordenadora do Programa de Pós-graduação em Gestão e Avaliação da Educação Pública e da UAB (UFJF); Líder do grupo EDUCCO. ORCID: 0000-0003-0703-3991.

E-mail: mborges.eliane@gmail.com

\section{RICARDO DUCATTI COLPAS}

Universidade Federal de São João Del-Rei (UFSJ). Doutor em Desenvolvimento Humano e Tecnologias pela Universidade Estadual Paulista (UNESP); Professor do Departamento de Ciências da Educação Física e Saúde UFSJ; Líder do grupo de Pesquisa Interdisciplinar e Práticas Pedagógicas em Educação Física. ORCID: 0000-0001-7116-4481.

E-mail: ricardo@ufsj.edu.br 


\section{EM DEFESA DAS TECNOLOGIAS DE INFORMAÇÃO E COMUNICAÇÃO NA EDUCAÇÃO BÁSICA: diálogos em tempos de pandemia}

Este artigo objetiva problematizar algumas medidas emergenciais adotadas na educação básica durante a crise global do COVID-19. Dizem respeito ao uso das Tecnologias de Informação e Comunicação (TIC), excepcionalmente, como ferramentas que possibilitam o ensino a distância e visam minimizar os impactos imediatos do fechamento das escolas. Compreende a integração das TIC, como televisão, mídia impressa e mídia digital, oportuna e pertinente para o momento incerto, visando garantir acesso à educação ao maior número de estudantes. Essas medidas favorecem, principalmente, aqueles alunos que não possuem internet em suas residências. Em continuidade, apresenta a metodologia dos Episódios de Aprendizagem Situados como possível contribuição relevante aos esforços de desenvolvimento de uma "revolução digital inclusiva" pós-pandemia nas escolas. Essa metodologia aparece como potencialmente capaz de propiciar processos educativos relacionais entre ambientes formais e informais, com foco na interação, no diálogo e na pesquisa, por meio da utilização crítica das TIC no ensino e aprendizagem.

Palavras-chave: Educação. TIC. Pandemia.

\section{IN DEFENSE OF INFORMATION AND COMMUNICATION TECHNOLOGIES IN BASIC EDUCATION: dialogues in times of pandemics}

This article aims to discuss and problematize some emergency measures adopted in basic education during the global crisis of COVID-19. They relate to the use of Information and Communication Technologies (ICT), exceptionally, as tools that enable distance learning and aim to minimize the immediate impacts of school closures. It includes the integration of ICT, such as television, print and digital media, which are timely and relevant to the uncertain moment, aiming to guarantee access to education for the largest number of students. These measures favor, mainly, those students who do not have access to the internet in their homes. In continuity, it presents the methodology of Situated Learning Episodes as a possible relevant contribution to the efforts to develop a post-pandemic "inclusive digital revolution" in schools. This methodology appears as potentially capable of providing relational educational processes between formal and informal environments, with a focus on interaction, dialogue and research, through the critical use of ICT in teaching and learning.

Keywords: Education. ICT. Pandemic.

\footnotetext{
plurais 


\section{EN DEFENSA DE LAS TECNOLOGÍAS DE LA INFORMACIÓN Y LA COMUNICACIÓN EN LA EDUCACIÓN BÁSICA: diálogos en tiempos de pandemia}

Este artículo tiene como objetivo problematizar algunas medidas de emergencia adoptadas en la educación básica durante la crisis global de COVID-19. Se relacionan con el uso de las Tecnologías de la Información y la Comunicación (TIC), excepcionalmente, como herramientas que permitan el aprendizaje a distancia y apuntan a minimizar los impactos inmediatos del cierre de escuelas. Incluye la integración de las TIC, como la televisión, los medios impresos y digitales, que considera oportuno y relevante para el momento incierto, con el objetivo de garantizar el acceso a la educación para un mayor número de estudiantes. Estas medidas favorecen, principalmente, a aquellos estudiantes que no tienen acceso a internet en sus hogares. En continuidad, presenta la metodología de los episodios de aprendizaje situado como una posible contribución relevante a los esfuerzos para desarrollar una "revolución digital inclusiva" postpandémica en las escuelas. Esta metodología parece potencialmente capaz de proporcionar procesos educativos relacionales entre entornos formales e informales, con un enfoque en la interacción, el diálogo y la investigación, a través del uso crítico de las TIC en la enseñanza y el aprendizaje.

Palabras clave: Educación. TIC. Pandemia. 


\section{EM DEFESA DAS TECNOLOGIAS DE INFORMAÇÃO E COMUNICAÇÃO NA EDUCAÇÃO BÁSICA: diálogos em tempos de pandemia}

\section{Introdução}

Com base na mídia-educação, Miranda e Fantin (2018) nos ensinam que os usos das tecnologias de informação e comunicação (TIC) nas e pelas escolas devem ser entendidos como possibilidades de expressão, compreensão do mundo e, igualmente, oportunidade de interação. Para além da modernização do ensino ou atualização das aulas, essa relação necessariamente envolve outro tipo de atuação de professores e alunos, em síntese, um entendimento do processo ensino-aprendizagem para além da simples transmissão de conteúdo.

Pensamos, nesse processo, a importância do diálogo prévio, apresentando a proposta e suas potencialidades, inclusive à família, bem como sua importância. Pensamos, também, a importância de valorização do presencial na educação básica, por mais que as TIC e as competências tecnológicas sejam importantes no atravessamento desse cenário. Não se trata das TIC superarem o professor ou o ensino presencial, mas delas potencializarem o papel do professor e o ensino presencial, bem como o inverso!

$\mathrm{O}$ ano de 2020 nos apresentou desafios educativos e sociais que, no nosso entendimento, devem ser amplamente considerados no que diz respeito aos estudos das TIC e das competências midiáticas nas escolas. Esses desafios emergem do alastramento do COVID - 19 (coronavírus), que provocou morte, medo e mudanças de hábitos no mundo. No Brasil e na maioria dos países a quarentena foi adotada como principal medida de combate a esse novo vírus, descoberto no último dia do ano de 2019 supostamente na China. ${ }^{1}$

No nosso país, decretos de calamidade pública foram emitidos ainda no início do ano de 2020 especificando o que permaneceria aberto e o que seria suspenso durante a necessidade de isolamento social. Inicialmente, puderam funcionar apenas estabelecimentos considerados essenciais, como farmácias e mercados. Posteriormente, houve certa flexibilidade, permitindo a reabertura

1 Segundo a Organização Mundial da Saúde a origem do vírus ainda não está definida.

\section{plurais


parcial de atividades comerciais. Para isso foram estipuladas algumas normas de segurança, como a proibição de aglomerações.

Foram criados canais de denúncia de aglomerações em diversas localidades. Na Paraíba, além dos números 190 e 193, a população fez uso do aplicativo "SOS cidadão", que enviava diretamente às denúncias as forças de segurança locais (APLICATIVO SOS CIDADÃO, 2020). No município de Viana, no Espírito Santo, e na cidade do Rio de Janeiro as prefeituras criaram canais de atendimento chamados "disk-aglomeração" via WhatsApp (CORONAVÍRUS, 2020; PREFEITURA, 2020).

De todos os cenários, o da educação repercute como um dos mais preocupantes e de difícil solução, uma vez que, majoritariamente, se constrói por aglomerações. Escolas e universidades foram as primeiras instituições a cancelar suas atividades. A estimativa da UNESCO (HOW, 2020) para a Educação, datada do final de abril de 2020, era a de que o fechamento de instituições de ensino já atingia um total de 1,5 bilhão de estudantes em 191 países.

Frente a esse cenário inesperado, esforços tecnológicos foram adotados no sentido de transição do aprendizado presencial para o aprendizado on-line de maneira emergencial. Essas medidas geraram inúmeras repercussões. Uma delas diz respeito às disparidades econômicas que, por vezes, negam o acesso às novas TIC a uma parcela das camadas mais pobres. Outra, quanto à dificuldade operacional dos professores com as tecnologias.

O objetivo deste artigo é o de problematizar algumas medidas adotadas no sentido de tentar minimizar os impactos referentes a essa crise global de ensino e aprendizagem na educação básica via TIC. Alguns governos integraram mídias tradicionais (impressa e televisão) às mídias digitais (acesso a internet via celulares e computadores) no sentido de facilitar e democratizar a continuidade da Educação, principalmente a das comunidades mais vulneráveis e desfavorecidas.

Feito isso, nos somamos a outra preocupação da UNESCO (STARTING, 2020) neste dramático momento. A organização tem se preocupado em desenvolver respostas universais e equitativas no que diz respeito a uma "revolução digital inclusiva". Tentando humildemente contribuir, temos 
também como objetivo apresentar uma metodologia desenvolvida pelo professor Pier Cesare Rivoltella (2013) que pode se somar aos esforços de desenvolvimento de competências midiáticas autônomas pós-pandemia.

\section{TIC, educação e pandemia}

Diante do caótico cenário pandêmico, é fundamental nos posicionarmos desde já a favor do ensino presencial na educação básica. Isso evita margens para o oportunismo de algumas propostas empresariais, no caso brasileiro, via grupos educacionais que tem suas ações negociadas na bolsa, como a "Kroton Educacional" (LEHER, 2020). Só a educação presencial pode, de fato, dar conta de algumas necessidades educativas específicas, como, por exemplo, o atendimento especial para os deficientes, a garantia da merenda tão importante a inúmeras crianças, a proximidade, a interação direta, o toque e as práticas corporais com os colegas nas aulas de Educação Física.

Embora tenham existidos diversos esforços visando garantir acesso à educação via TIC durante a pandemia, agora está mais claro do que antes que o ensino e a aprendizagem não podem se limitar ao "à distância", tampouco aos meios on-line. Esse é também o entendimento da diretora geral da UNESCO (STARTING, 2020) Stefania Gianini. Caso limitasse, além do acesso, a própria dificuldade no manuseio das mídias, tanto dos professores quanto de alguns alunos, seria fator de exclusão.

Todavia, de maneira excepcional, diante da necessidade de isolamento social e da incerteza da duração da pandemia, tivemos nas TIC a oportunidade de mitigar o impacto imediato do fechamento das escolas. Inspirados em Sousa Santos (2020) questionamos: quais os potenciais medidas poderiam ser tomadas pela educação diante a pandemia do coronavirus na ausência das TIC? Respondemos: o total abandono dos nossos alunos.

Para a maioria dos governos, pensar alternativas de possibilidades educativas diante da pandemia foi, na medida do possível, uma das prioridades (COVID-19, 2020). Argentina, Croácia, China, Chipre, Egito, França, Grécia, Itália, Japão, México, Portugal, República da Coréia, Arábia Saudita, Emirados Árabes Unidos e Estados unidos compõem essa lista segundo a UNESCO (HOW, 2020).

\footnotetext{
plurais 
A maioria dos países adotou ou ampliou as combinações tecnológicas nesse processo, por meio principalmente de plataformas on-line, para garantir aprendizagem contínua.

Em quase todos os países, professores e administradores de escolas são incentivados a usar aplicativos para apoiar a comunicação com alunos e pais, bem como ministrar aulas ao vivo ou gravar aulas em estilo massivo aberto on-line (MOOC). O conteúdo do aprendizado também é fornecido pela TV e outras mídias (HOW, 2020, p. 01)

Assim como Nóvoa (2020) concordamos que a presença da escola se faz mais importante nos momentos de crise. Nesse momento de isolamento social é fundamental que os professores, pedagogos, coordenadores e diretores não abandonem seus alunos às suas respectivas sortes. Caso contrário, podemos fazer uma analogia entre os filhos que crescem sem pai e os alunos que nos momentos mais difíceis se veem sem o amparo dos educadores. O resultado é que no futuro ambos, alunos e filhos sem pai, não confiarão naqueles que, diante da dificuldade, os deixaram.

Todavia, $43 \%$ do número total de alunos (cerca de 706 milhões) mantidos fora da sala de aula pela pandemia do COVID-19 no mundo não têm acesso à internet em casa. Nos países mais pobres as disparidades aumentam ainda mais, na África Subsaariana, $82 \%$ dos alunos não possuem acesso á internet (STARTING, 2020). Isso torna o ensino a distância digital uma ferramenta que pode contribuir com o processo de ensino e aprendizagem, contudo, não de maneira a gerar equidade.

Se, para grande parte das escolas privadas, não houve hesitação quanto à alternativa do trabalho virtual, no que diz respeito às escolas públicas brasileiras, paira, neste momento, uma grande discussão entre adotar ou não o uso das TIC em atividades remotas no processo educativo durante o isolamento. Aqueles que são contra alegam, além da falta de preparo de professores e a eventual exploração de seu trabalho pelo aumento de carga horária, que uma parcela dos alunos, devido à pobreza, não possui acesso às tecnologias, principalmente àquelas que exigem acesso à internet. Esses alunos estariam excluídos da possibilidade de acompanhar as atividades a distância e, inclusive, de serem avaliados sobre as atividades. Há ainda a preocupação dos críticos apoiam a essa possibilidade, de uma educação conteudista, como eles entendem que costuma ser a educação a distância.

Por outro lado, os que a utilização das tecnologias, entendem ser essa uma solução plausível, provisória e única diante o atual cenário de incertezas quanto ao momento de retorno à escola. Que, 
além disso, são os alunos mais pobres, mais frágeis, mais vulneráveis que precisam dos professores e da escola neste momento, principalmente como suporte e apoio emocional. Os outros alunos terão em casa um conjunto de possibilidades de manterem, durante a pandemia, o seu percurso de aprendizagem e de suprirem suas necessidades de afeto, sentimentos e emoções.

Como diz o ditado popular, "nem muito ao céu e nem muito ao inferno". Por mais que saibamos a precariedade da realidade de muitas famílias brasileiras, a dificuldade que assola a população pertencente às periferias, por exemplo, entendemos que a escola pública não pode se ausentar do processo educativo neste momento, independentemente dos argumentos. Que fique claro que não se trata de um processo de exclusão, mas, ao contrário, se trata de uma tentativa de inclusão. Para os nossos alunos o simbolismo do afeto, no ato da escola garantir o processo educativo na atual conjuntura, pode ter mais importância do que o processo educativo em si.

A perspectiva interacional nos faz considerar esse processo da escola e dos professores presentes na vida dos alunos na atual conjuntura, via tecnologias, como possibilidade de atenção pautada na mobilização da empatia (BERTHOZ, 2009; GOLEMAN; SENGE, 2014; RIVOLTELLA, 2012). Contribui para desconstruir possíveis individualidades que o próprio isolamento social possa ajudar a desenvolver. Inclusive para potencializar esse processo, os professores podem indagar os alunos quanto à importância das ações colaborativas que vêm sendo adotadas no combate à disseminação do vírus.

A mobilização da empatia apresenta a possibilidade da mudança de pontos de vistas ou da reafirmação de alguns deles, inclusive no que diz respeito à compreensão do aluno quanto ao próprio professor e à escola nos momentos de dificuldade. A escola, ao se fazer presente na casa dos alunos, ou ao menos ao demonstrar a intenção de se fazer presente em um período tão conturbado apresenta, pragmaticamente, a desconstrução de referenciais egocêntricos por meio da percepção empática. O que não ocorre, ou ocorre de forma inversa, caso a escola opte por nada fazer.

A interação pedagógica viabilizada por meio de tecnologias tem o potencial de promover, particularmente pela comunicação de imagens, rememoração de experiências de pertencimento, afetividade e companhia. É o que nos propõe a neurociência, quando explica que imagens podem gerar boas lembranças que, consequentemente, guiam movimentos integradores e conectores, incidindo positivamente na qualidade de vida dos alunos que estão confinados (DAMÁSIO, 2018).

\author{
plurais


As estruturas cerebrais gerenciam a conversão das imagens recebidas em símbolos, linguagens e afetos. Nas telas exibidas em casa, no contexto da relação educação-tecnologia, as crianças podem ver os professores, podem ver os colegas e até mesmo se ver em momentos vividos na escola. Graças à mente humana, elas têm a oportunidade de traduzir essas imagens em códigos verbais, gerando diversos tipos de respostas positivas.

Nesse período de isolamento social, uma das formas de enriquecimento da mente humana pode se dar baseada nesse movimento de imagens recuperadas na memória via TIC. Nessa interação os alunos têm a possibilidade de (re)criar internamente imagens do universo que os circunda. Em outras palavras, essa tensão proporcionada ou potencializada pelo uso das TIC, pode desencadear imagens a ponto de que sejam criadas narrativas de situações, fatos e conteúdos internos e externos ao ambiente que naquele momento limita fisicamente os alunos.

Retomando, mas como manter o senso de equidade no acesso à aprendizagem via TIC em um momento tão excepcional como o vivido? A resposta está no uso das mais diversas TIC como ferramentas. Incluindo o uso de transmissões de rádio, transmissões de TV, impressão e envio de mídias impressas via Correios e também os meios on-line por intermédio de computadores, tablets e especialmente celulares. Segundo a pesquisa "TIC domicílios" (2020), o meio principal de acesso à internet no Brasil, por exemplo, é o celular (97\%),

Dentre algumas medidas tomadas ao longo do mundo na relação entre TIC, equidade e educação, podemos citar a China, que forneceu computadores, pacotes de dados móveis e subsídios de telecomunicações para estudantes de famílias de baixa renda. A França, por sua vez, emprestou dispositivos e forneceu tarefas impressas para 5\% dos alunos que não possuem acesso a internet ou acesso a computadores no país. Portugal sugeriu uma parceria com a empresa dos correios para entregar materiais impressos educativos em casa (HOW, 2020).

No sentido de garantir o processo educativo e acolher os alunos, na linha do que pensa António Nóvoa (2020), o governo do Espírito Santo e o de São Paulo parecem dar um salto à frente dos outros Estados brasileiros ao incluir, juntamente com a proposta de aplicativos de celulares, também a televisão como espaço de aprendizagem. Essa relação é fundamental se considerarmos que $96,5 \%$ dos domicílios brasileiros possui TV, segundo a última pesquisa do IBGE de amostra 
de domicílios, realizada em 2017. Retomamos o modelo muito divulgado no Brasil com o nome de Telecurso 2000 e, segundo Nóvoa (2020), chamado de Telescola em Portugal, nos anos de 1960.

Com o nome de "Escolar", as aulas no Espírito Santo, a partir do dia 15 de Abril de 2020, passaram a se dar pela televisão aberta (canais 8.2, 8,3 e 8.4), com conteúdo para todos os anos, e por um aplicativo do celular no qual o estudante interage com o professor por meio de salas de aulas virtuais, sem a necessidade de acesso à internet depois de baixado. A ideia foi desenvolvida, inicialmente, sem considerar os dias letivos. Segundo o secretário de Educação do Espírito Santo, Professor Heliosandro Mattos, "são apenas medidas para manter o vínculo entre o aluno e o professor, e diminuir a evasão escolar.” (COMETTI, 2020)

Em São Paulo o governo foi além. Junto à utilização do uso da plataforma on-line e da TV para garantir as atividades pedagógicas, foram distribuídos kits de material escolar para 3,5 milhões de crianças da rede estadual de ensino (GOVERNO, 2020). Todavia, o kit não contempla todas as disciplinas previstas para os alunos, apenas matemática e português. Nele também constam gibis da turma da Mônica, livro literário adaptado à idade e fascículo de orientação. Além disso, o material também contempla informações aos pais dos alunos.

Compreendemos as medidas propostas pelo Governo do Espírito Santo e de São Paulo como oportunas e pertinentes em um momento excepcional. Todavia, logo que passe a pandemia temos que ter a capacidade de regressarmos ao que Nóvoa (2020) denomina de certa normalidade, mas com consciência de que a crise nos demonstrou, claramente, a importância do diálogo das escolas com as tecnologias, via práticas pedagógicas. Cabe ressaltarmos que não é coerente que pensemos em abrir mão do encontro, do face a face, do contato direto, do trabalho cooperativo entre alunos e alunos, professores e alunos, por mais que nessa relação às tecnologias devam fazer-se presentes.

A “metamorfose educativa", a inclusão das tecnologias no processo educativo, deve ser pensada após a retomada de certa normalidade, com o cuidado de não fazermos a defesa de qualquer projeto homescholling. Sabemos que existem diversos interesses empresariais e políticos nessa proposta pensada, inclusive, por velhos conhecidos como o Banco Mundial. O movimento "Todos pela Educação" é um exemplo disso (EVANGELISTA; LEHER, 2018; RIBEIRO, 2019; COSTA E SILVA, 2019; BATISTA; MENDES, 2020).

\footnotetext{
plurais 
Nesse jogo de disputa empresarial e política pela Educação, devemos ter o máximo de atenção e criticidade. Os movimentos articulados pelos grandes empresários utilizam de ideias que muito se assemelham aos argumentos apresentados por Miranda e Fantin (2018), Nóvoa (2020) e por nós, ao longo deste texto. Essa estratégia discursiva se traveste de progressismo educativo-tecnológico para inserir as mais variadas empresas, dentre elas as de telecomunicação, na política educativa. Aparentam preocupação com os "excluídos digitais", mas, na verdade, querem fazer valer seus interesses empresariais, que se referem, fundamentalmente, menos ao direito à educação que às possibilidades de lucro.

Entretanto, a utilização desses argumentos tecnológicos pelo empresariado em prol da implementação do que denomina de "educação remota" não deve nos fazer negar a importância da relação tecnologias e educação. Sabemos que diversos pesquisadores nacionais e internacionais sérios, que não apresentam qualquer tipo de viés empresarial, defendem essa proposta há certo tempo (BARBERO, 1998; 2014 BAZALGETTE, 1989; 2000; BELLONI, 1984; 1991; 1992; 2001; 2008; BUCKINGHAM; 2005; 2006; FANTIN, 2006; 2008; 2009; 2010 GONNET, 2001; 2004; MASTERMAN, 1985; 1994; 1997; RIVOLTELLA, 2001; 2005; 2006; 2007; SILVERSTONE, 1999). Seria, no mínimo, inconsistente a negação de tantos anos de pesquisa em nível mundial sob $\mathrm{o}$ argumento de que todas apresentam interesses econômicos.

Em seu estudo, Fantin (2006) pondera que as TIC são apresentadas como possibilidades de renovação de nossas práticas pedagógicas e da própria escola em relação às exigências do contemporâneo. Elas não se colocam em disputa com os professores. Pelo contrário, são elas meios para que os professores consigam efetivar suas aulas de modo mais proximal e atrativo aos alunos e, ao mesmo tempo, para que eles possam educar para o uso crítico das tecnologias.

Por mais que sejam tecidas críticas que situam esse diálogo como secundário, as tecnologias na escola, aliada a professores formados para sua utilização (SILVEIRA, BRUGGEMANN, BIANCHI, 2019), garantem a inclusão de diversos jovens vulneráveis em um processo que já faz parte do cotidiano daqueles que pertencem a classe média e classe média alta, por exemplo. Para os jovens que já convivem com essas tecnologias, essa inclusão pode contribuir com um olhar mais crítico diante delas (FANTIN, 2006).

Pensando em como o contemporâneo tem se organizado e que a escola não pode se ausentar dessa organização, sob o risco de perder relevância, vemos como oportunidade de busca pela 
equalização social, de tentativa de um menor distanciamento, e também de problematização crítica das tecnologias na educação, a metodologia dos episódios de Aprendizagem Situados, de autoria do professor italiano Pier Cesare Rivoltella (2013).

\section{A metamorfose educativa pós-coronavírus: uma leitura com as tecnologias e a metodologia dos Episódios de Aprendizagem Situados}

A metodologia dos Episódios de Aprendizagem Situados (EAS) pode contribuir no processo necessário de renovação educativa, tecnológica e crítica. Em outras palavras, na mobilização da relação entre contextos, conhecimentos formais e informais em prol de compartilhamento e desenvolvimento de habilidades e atitudes socioculturalmente constituídas na relação entre educação e tecnologias via didática.

Tanto os saberes que o indivíduo aprende por si, de maneira autônoma ou informal, quanto os saberes que aprende por intermédio da transmissão de outras pessoas, como professores, de maneira formal, possuem relevância educativa, desde que forjados em situações de criticidade em determinado contexto. A partir de uma proposta didática, a EAS pode contribuir na aproximação da cultura escolar com as experiências que ocorrem com as tecnologias ou em rede (on e off-line), ampliando os contextos de aprendizagem. Isso seria relevante para suprir certos descompassos entre as demandas emergentes nos usos tecnológicos e os desafios da contemporaneidade postos à escola.

Hobbs (2017) assinala que as tecnologias são parte do ambiente cultural contemporâneo. Estão presentes nas práticas culturais e sociais dos nossos alunos. Os ajudam a solucionar problemas (tutoriais do YouTube), a se informarem (telejornais, postagens nas mais variadas redes sociais), a se divertirem (filmes, desenhos, novelas, séries e jogos disponíveis online e na própria televisão), dentre outros processos da vida cotidiana como namoro e amizade. Nesse sentido, Miranda e Fantin (2018) afirmam que as tecnologias possuem características importantes para o ensino e aprendizagem no contemporâneo. Isso reforça a necessidade do cenário formal escolar contribuir no desenvolvimento de competências das crianças e jovens para esse processo.

Segundo a pesquisa “TIC Domicílios” de 2019, 70\% da população brasileira está conectada. Na mesma linha, o "Relatório Digital in 2019" afirma que a penetração da internet atingiu 70\%, acima da média global de 57\%. 85\% dos usuários de internet do Brasil navegam na web todos os dias. O Brasil fica atrás apenas das Filipinas em termos de horas gastas na internet, passando um total de $9 \mathrm{~h} 29 \mathrm{~m}$ por dia, bem acima da média global de $6 \mathrm{~h}$ e $42 \mathrm{~min}$.

\section{plurais}


Quase metade da população rural (49\%) e das classes D e E (48\%) tinha acesso a internet em 2019. Nas regiões urbanas, a conexão chegava a 74\%. O meio principal de acesso a internet é o celular (97\%), seguido do computador (43\%) que vem a cada ano perdendo adeptos. Ele era meio de acesso a internet de $80 \%$ dos usuários em 2014. Na zona rural o uso do celular se acentua, $77 \%$ dos brasileiros se conectam exclusivamente por ele, enquanto apenas $20 \%$ utilizam o computador.

Entre as famílias que ganham até 1 salário mínimo o uso exclusivo do celular chega a 78\% dos usuários, enquanto o computador a 19\%. Entre as famílias com renda familiar entre 1 e 2 salários mínimos, a presença do computador sobe para $31 \%$ dos usuários e o uso do celular cai para $63 \%$. Para os mais ricos, com renda acima de 10 salários mínimos, o uso exclusivo do celular é feito pro apenas $17 \%$ dos usuários, enquanto $80 \%$ utilizam computador e celular para se conectar. Dentre a população usuária de internet $89 \%$ utiliza quase todo dia. Nas classes D e E 78\%.

\section{Conexão por classe social}

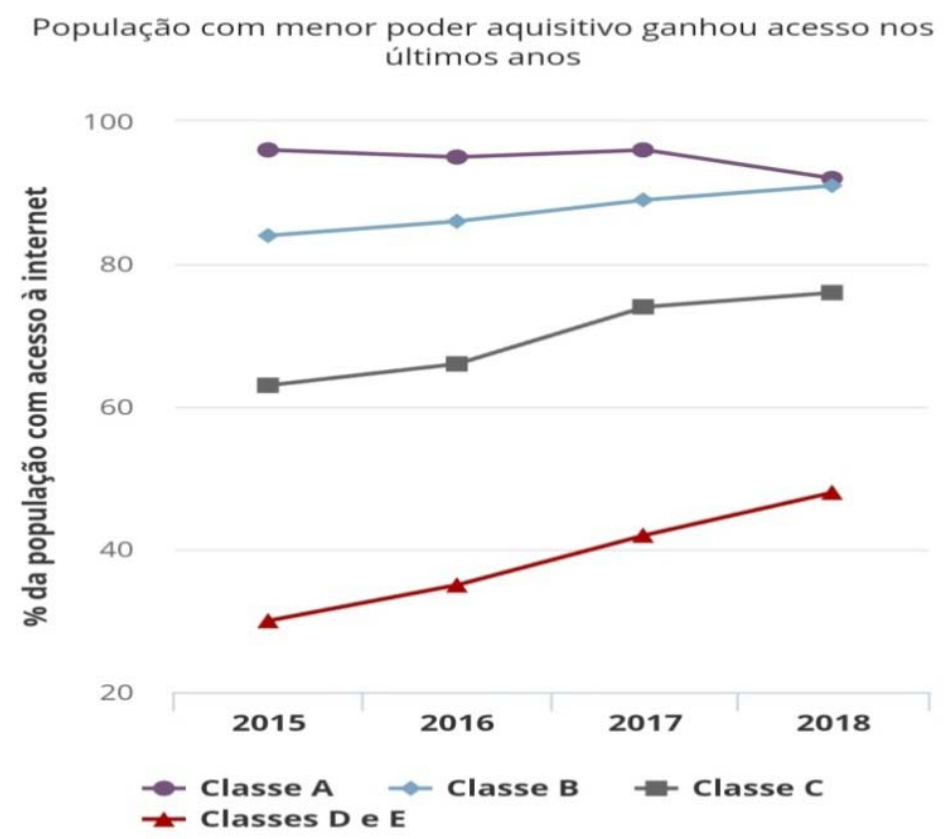

Fonte: TIC Domicílios 
A pesquisa indica que o Brasil apresenta um crescimento importante nos indicadores de utilização da internet, inclusive com as classes mais pobres. Nos países desenvolvidos da América do Norte e Europa $80 \%$ da população, em média, utiliza a internet. Países em desenvolvimento do leste europeu ficam em torno de 50\% a 60\%. O Brasil se encontra numa posição intermediária, $70 \%$ de usuários de acordo com a pesquisa.

As redes sociais ocupam no Brasil o segundo lugar em termos de horas gastas por dia: 3horas e 34 minutos. $81 \%$ dos brasileiros com 13 anos ou mais estão ativos nas redes sociais, contra $58 \%$ em média no resto do mundo. O alcance orgânico médio dos posts na página do Facebook no país é de $8,5 \%$, enquanto globalmente chega a $8 \%$. A taxa de engajamento no país é de $4,22 \%$, enquanto a média no mundo é de 3,75\%. O YouTube é a rede social mais utilizada no Brasil (95\%), seguida do Facebook (90\%), do WhatsApp (89\%) e do Instagram (71\%).

Quanto à televisão, o Instituto Brasileiro de Geografia e Estatística (IBGE) divulgou em 2017 a "pesquisa nacional por amostra de domicílios" que apontava que praticamente todos os domicílios $(96,7 \%$ ) brasileiros possuíam ao menos um aparelho de televisão, enquanto $3.3 \%$ não possuíam. A região norte do Brasil era detentora do maior percentual de domicílios sem televisão, $7,2 \%$, enquanto a região sudeste era a que tinha nesse o menor indicador, $2,2 \%$.

Com esse panorama, torna-se importante a construção de algumas competências midiáticas por meio da escola, no Brasil. Não sendo essa justificativa suficiente, é atrativa para os alunos a utilização das tecnologias na escola, podendo elas estimular a aprendizagem, principalmente por fazerem parte dos seus cotidianos. Todavia, não devemos cair no conto salvacionista das tecnologias, do discurso integrado, de que elas seriam a salvação. Sua inserção, por si só, não modifica funções e relações existentes na escola (RIVOLTELLA, 2013).

O trabalho didático com as tecnologias, portanto, pode ser pensado pelo professor em três frentes: tendo as tecnologias como ferramentas instrumentais ou suportes de ensino (filmes, imagens, áudios, televisão, redes sociais...); meios para análise crítica (análises do que é veiculado pelas mais diversas mídias, inclusive sociais); e até mesmo produção de mídias na escola (audiovisual, games, blogs...). Na mídia-educação denominamos de Educação para, com e através das mídias (FANTIN, 2006).

\footnotetext{
plurais 
Os preceitos da metodologia dos Episódios de Aprendizagem Situados (EAS) possibilitam aos alunos um agir competente com as tecnologias dentro e fora da escola. Nesse agir eles mobilizam, compartilham conhecimentos, habilidades e atitudes socioculturalmente constituídas. Essa metodologia proposta por Rivoltella (2013) e desenvolvida por Fantin (2015) e por Miranda e Fantin (2018), pode contribuir, inclusive, para que em supostos acontecimentos como o ocorrido em 2020 devido ao COVID- 19, no qual as tecnologias são demandadas quase que de maneira única, os alunos tenham internalizadas habilidades formativas capazes de orientá-los na construção do conhecimento, na recepção do conhecimento e na divulgação de conhecimentos a partir das tecnologias, sejam elas quais forem.

O conceito de Episódio de Aprendizagem Situado (EAS) se origina no interior da reflexão do Mobile Learning/Aprendizagem móvel e nas atividades de microlearning/microatividades, impulsionadas pela cultura digital e suas fragmentações e recombinações de formatos textuais e transmidiáticos. A partir dessas reflexões, tornam-se possíveis outras possibilidades de estruturação do agir didático, da aula, ou seja, da aula, do planejamento e da avaliação (FANTIN, 2015; RIVOLTELLA, 2013).

Nos fundamentos na neurociência a EAS busca atualizar os saberes sobre como aprendemos. Rivoltella (2012) e FANTIN (2015) destacam três modalidades fundamentais de aprendizagem que têm como pano de fundo as emoções: experiência/ensaio e erro, repetição/e exercício e imitação. A partir dessas modalidades o professor pode se atentar para uma aprendizagem mais significativa, com sentido e coerente com a forma com que nosso cérebro aprende, como pondera também Goleman (2014).

Nessa linha de problematização da aprendizagem, é fundamental que sejam consideradas a dimensão subjetiva e os contextos socioculturais. Por exemplo, se nos espaços de educação informais a aprendizagem acontece de forma intuitiva, é importante que a escola e os professores tenham essa clareza para retomar o que se aprende e transformar informação em conhecimento. Essa passagem do implícito para o explicito, do fragmentado para o integrado, é função da educação formal, inclusive, na relação dos alunos com as tecnologias.

Assim, o aluno é considerado pela EAS como construtor de conhecimentos e aprendizagem baseado em cinco modalidades principais: a) aquisição, ou identificação de um tema de interesse/ 
pesquisa para aprofundar; b) pesquisa, ou busca de informações relevantes para a síntese; c) organização e discussão das informações para apresentar; d) prática ou socialização da parte mais importante do trabalho feito; e e) colaboração por meio de perguntas e críticas aos trabalhos dos colegas, sustentando a discussão com argumentos (FANTIN, 2015; MIRANDA; FANTIN, 2018).

A EAS tem suas ideias inspiradas em Freinet (2002). A principal está na lição a posteriori e no trabalho cooperativo entre pares. Outra está na forma de operar com o conhecimento baseado em um saber de ação, feito de inteligência situacional, metacognição, consciência crítica e protagonismo do aluno. Nesse sentido, as culturas das mídias atuais, presentes no cotidiano da maioria dos alunos, adentram a escola como pequenas unidades de saber (microlearning).

Para que isso se efetive, as aulas são desenvolvidas em três momentos/elementos: i) momento preparatório/prévio, no qual a aprendizagem se dá por aquisição e pesquisa, por meio de atividades (situações-estímulos) que promovam a experiência dos alunos aos conceitos iniciais e sobre o tema em questão (vídeo, imagem, experiência, documento, depoimento); ii) momento operatório/operativo no qual são promovidas atividades de produção (inclusive midiáticas) incitando a aprendizagem por meio de prática e colaboração sobre a situação-estímulo; e iii) o momento reestruturador, reservado a discussão, sistematização e retomada dos conceitos de modo compartilhado nos momentos anteriores. Objetiva-se nesse último momento a consciência dos processos desenvolvidos e seus resultados, a fim de fixar aspectos que merecem ser destacados (FANTIN, 2015; MIRANDA; FANTIN, 2018; RIVOLTELLA, 2013).

\begin{tabular}{|l|l|l|}
\hline \multicolumn{1}{|c|}{ MOMENTO EAS } & \multicolumn{1}{c|}{ AÇÕES DIDÀTICAS } & \multicolumn{1}{c|}{ APRENDIZAGEM } \\
\hline Preparatório & $\begin{array}{l}\text { Fazer experiência, conceitualizar, } \\
\text { analisar }\end{array}$ & Por aquisição, por pesquisa. \\
\hline Operatório & Analisar, aplicar & $\begin{array}{l}\text { Através da prática, por colabo- } \\
\text { ração }\end{array}$ \\
\hline Reestruturador & Discutir, publicar & $\begin{array}{l}\text { Através da discussão, por cola- } \\
\text { boração }\end{array}$ \\
\hline
\end{tabular}

Fonte: RIVOLTELLA, 2013; FANTIN, 2015.

Nessa metodologia, os momentos ou elementos estão organicamente articulados. Seu ritmo é o ternário da didática: "encontre, elabore e compartilhe", "compreenda, aja e reflita", e "pesquise,

\author{
plurais \\ Salvador, v.5, n.1 p.146-169, jan/abr. 2020
}


compartilhe e apresente. Suas ações-chave dizem respeito aos momentos de: entrar em contato com as informações (buscar/pesquisar/encontrar); apropriar-se criticamente (compreender); produzir informações e críticas (elaborar/desconstruir/reorganizar/agir); refletir (metacognição); e compartilhar (publicação).

Rivoltella (2013) e Fantin (2015) compreendem ainda que, do ponto de vista da neurociência cognitiva, da neurodidática e da bioeducação o conceito de EAS potencializa os cenários básicos de aprendizagem humana: 1) sobre a experiência, no momento de antecipação e operatório; 2) por modelagem ou imitação, no momento de antecipação (em relação aos exemplos dados e às situações-estímulos propostas, no momento operatório (ao envolver atividades colaborativas em que as resoluções de problemas possam ser confrontadas, e no momento reestruturador (durante as sínteses e sistematizações); e 3) o de natureza simplexa, no qual são elaboradas estratégias novas e complexas para lidar com as complexidades dos desafios educativos, na criação por inibição (atividade prévia precedida de um levantamento preliminar do aluno e uma moldura conceitual preparada pelo professor das decisões antecipatórias das capacidades de excluir certas soluções para buscar o que realmente interessa), na rapidez (no limite de tempo de uma aula), na seleção (esforço de identificação e seleção de informações relevantes e concentração no que realmente é importante do ponto de vista didático); 4) das raízes enativas, na centralidade da orientação do professor (assumindo a situação didática, sua regulação e entendimento).

Essa proposta de trabalho com as TIC na escola permite ao aluno seu desenvolvimento em outros espaços que também fazem uso das TIC, principalmente em sua casa, em uma perspectiva de aprendizagem informal continuada, que parte da experiência como resolução de problemas. Proposta que ressaltamos que em nada se aproxima da homeschooling, nem tampouco abdica da educação presencial, do fazer e do compartilhar. Todavia, potencializa as possibilidades de aprendizagem por meio das tarefas incorporadas, deixando os alunos mais preparados para situações nas quais é demandada autonomia e criticidade, como o que se vê no momento da pandemia.

A autonomia, naturalmente, virá se desenvolvendo e aprofundando ao longo do tempo, do estudo e das problematizações. O que, por outro lado, não impede que os alunos sejam educados para ela desde a mais tenra idade, uma vez que o contato com as tecnologias, seja ela qual for, acaba se dando desde a mais tenra idade. Amante (2007) já evidenciava razões para integrar as TIC 
em contexto pré-escolar. Na Finlândia, desde 2016, a alfabetização midiática inicia-se na escola primária (HENLEY, 2020). Seu foco é no pensamento crítico e na alfabetização noticiosa. Com a epidemia do COVID-19, ficou mais explicita a necessidade de sabermos reconhecer fake news, inclusive, para não as espalharmos.

Por fim, a proposta assume que não cabe à escola apenas a tarefa de ensinar conteúdos curriculares ou disciplinares, mas também contribuir para o desenvolvimento de condições para que os alunos saibam aprender criticamente com situações do seu cotidiano. Evidentemente, nosso foco está nas TIC, porém, outros diálogos são possíveis com a EAS. Os desafios da escola hoje se complexificam, por exemplo, diante de tantas informações advindas dos meios tecnológicos, algumas extremamente produtivas e confiáveis e outras nem tanto. A notar que nossos alunos também são parte desse cenário informacional, por serem, além de receptores, emissores em potencial de mensagens, por meio de posts, compartilhamentos e etc. Tal processo tecnológico, como outros, necessita de sensibilidade da escola na construção ou no redimensionamento de suas preocupações.

\title{
Considerações finais
}

A pandemia e a quarentena demandaram medidas excepcionais no cenário educacional mundial. Este artigo objetivou problematizar algumas medidas adotadas no sentido de tentar minimizar os impactos referentes a essa crise global de ensino e aprendizagem na educação básica via TIC. Além disso, também objetivou apresentar a metodologia EAS como possível contribuição aos esforços de desenvolvimento de competências midiáticas autônomas pós-pandemia.

Destacamos a relevância e a necessidade dos usos das TIC como ferramentas pedagógicas provisórias, considerando o fechamento das escolas e a incerteza quanto ao momento do seu retorno. Todavia, ressaltamos que faz-se necessário alternativas que busquem garantir o acesso a ampla maioria dos estudantes, principalmente para o mais pobres. No Brasil, as propostas do governo do Espírito Santo e de São Paulo de integração das TIC, incluindo a TV e as mídias impressas junto às mídias digitais, nos parecem oportunas e pertinentes.

É importante que a escola e os professores contribuam para que seus alunos não se sintam esquecidos/abandonados a própria sorte. A utilização da TV, da mídia impressa e da internet contribui

\author{
plurais


substancialmente para isso. Podemos dizer também que a pandemia, "pedagogicamente", nos oferece algumas lições na relação com as TIC. Enfatizamos a necessidade de pensarmos formas de construirmos uma "revolução digital inclusiva". Como possibilidade de contribuição, apresentamos a metodologia EAS como esforço didático integrativo, crítico e autônomo.

$\mathrm{Na}$ ausência de construção de novas estratégias pedagógicas, baseadas na pesquisa, na reflexão e na utilização crítica e criativa das TIC, o regresso a "normalidade" pós-pandemia nos fará continuar negando e obliterando a relevância da relação entre tecnologias e educação. Toda crise nos apresenta a oportunidade de mudança e ressignificação. Temos agora a oportunidade de, de fato, avançarmos para a construção de escolas que eduquem também para uma cultura que já é fortemente marcada pela presença das tecnologias. O que está em jogo é o próprio papel da escola diante de deslocamentos e tensões que se colocam hoje, nesse tempo de incertezas, e continuarão a nos interrogar pelos tempos que seguirão. Certamente, um momento privilegiado para questionar alguns paradigmas e elaborarmos novas propostas no sentido de reinvenção da escola.

\section{REFERÊNCIAS}

AMANTE, Lúcia As TIC na Escola e no Jardim-de-Infância: Motivos e Factores para a sua Integração. Sífiso, v. 3, n.1, 53 - 64, 2007.

APLICATIVO "SOS cidadão" é canal para denúncias sobre aglomeração de pessoas na região metropolitana da JP. Somos Todos Paraíba, Jaguaribe-PB, 23 mar. 2020. Disponível em: $<$ https://paraiba.pb.gov.br/noticias/aplicativo-2018sos-cidadao2019-e-canal-para-denuncias-sobre-aglomeracao-de-pessoas-na-regiao-metropolitana-de-jp >. Acesso em: 25 abr. 2020.

BATISTA, Zenaide Leão; MENDES, Odete da Cruz. A concepção de gestão subjacente na proposta oficial do plano de ações articuladas - PAR. Brazilian Journal of Development, v.6, n.3. p. 11264-11276, 2020.

BAZALGETTE, Cary. Primary media education. A curriculum stament. Londres: British Film Institute, 1989.

BAZALGETE, Cary. et al. Moving images in the classroom. A secondary teacher's guide to using film \& television. Londres: Cromwell Press, 2000. 
BELLONI, Maria Luiza. Technologie et éducation: Le systéme de télévision éducative au Brésil. Tese de doutorado. Universidade de Paris 5, 1984.

BELLONI, Maria Luiza. Educação para a mídia: Missão urgente da escola. Comunicação e Sociedade, n.17, 1991.

BELLONI, Maria Luiza. Programa Formação do Telespectador. Kit de materiais impresso e vídeo. Brasília: UnB/CIE, 1992.

BELLONI, Maria Luiza. O que é mídia-educação. Campinas: Autores Associados, 2001.

BELLONI, Maria Luiza. Infância e TIC: Aprendizagens, autodidaxia e colaboração. Paper apresentado no Congresso Internacional em Estudos da Criança, da Universidade do Minho, 2008.

BERTHOZ, Alain. La simplexité. Paris: Odile Jacob, 2009.

BUCKINGHAM, David. Media education: Literacy, learning and contemporany culture. Cambridge: Polity Press, 2005.

BUCKINGHAM, David. In la media education nelléra della tecnologia digitale. In: MORCELLINI, M; RIVOLTELLA, Pier Cesare. (orgs.) La sapienza di comunicare. Gardolo: Erikson, 2006.

COMETTI, Any. Com escolas fechadas, aulas da rede estadual do ES vão ser transmitidas pela televisão. G1/Globo, Vitória-ES, 14 abr. 2020. Disponível em: <https://g1.globo.com/es/ espirito-santo/noticia/2020/04/14/com-escolas-fechadas-aulas-da-rede-estadual-do-es-vao-ser-transmitidas-pela-televisao.ghtml>. Acesso em: 10 abr. 2020.

CORONAVIRUS: Viana cria canal de atendimento para denunciar aglomerações. A Gazeta, Vitória-ES, 22 abr. 2020. Disponível em: $<$ https://www.agazeta.com.br/es/gv/coronavirus-viana-cria-canal-de-atendimento-para-denunciar-aglomeracoes-0420 >. Acesso em: 25 abr. 2020.

COSTA E SILVA, Francely Priscila. A reforma do Ensino Médio no governo Michel Temer (2016 - 2018). Dissertação (Programa de Pós-graduação em educação) - Universidade Federal de Minas Gerais, Belo Horizonte, 2019.

COVID-19 Educational Disruption and response. UNESCO, Paris. Disponível em: $<$ https:// en.unesco.org/covid19/educationresponse> Acesso em 25 abr. 2020.

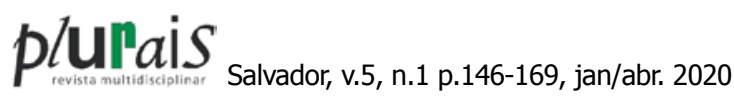


DAMÁSIO, António. A estranha ordem das coisas: As origens biológicas dos sentimentos e da cultura. São Paulo: Companhia das Letras, 2018.

EVANGELISTA, Olinda; LEHER, Roberto. TODOS PELA EDUCAÇÃO E O EPISÓDIO COSTIN NO MEC: A pedagogia do capital em ação na política educacional brasileira. Trabalho necessário, v. 10, p 1-12, 2018.

FANTIN, Monica. Mídia-educação: Conceitos, experiências e diálogos Brasil- Itália. Florianópolis: Cidade Futura, 2006.

FANTIN, Monica. A mídia na formação escolar de crianças e jovens. Anais do XXXI Congresso Brasileiro de Ciências da Comunicação. Intercom, Natal, 2008.

FANTIN, Monica. Formação cultural e mídia-educação na pedagogia. Anais do VI Congresso Internacional de Educação: Educação e Tecnologias. São Leopoldo: Unisinos, 2009.

FANTIN, Monica. Novos paradigmas da didática e a proposta metodológica dos Episódios de Aprendizagem Situada, EAS. Educação \& Realidade, v.40, n.2, p. 443-464, 2015.

FANTIN, Monica; RIVOLTELLA, Pier Cesare. Interface da docência (des)conectada: Isso das mídias e consumos culturais de professores. Anais da $33^{\mathrm{a}}$ reunião Anual da Anped. Caxambu, 2010.

FREINET, Celestin. La Scuola del Fare. Bergamo: Junior, 2002.

GOLEMAN, Daniel; SENGE, Peter. O foco triplo: Uma nova abordagem para a educação. Rio de Janeiro: Editora Objetiva, 2014.

HOBBS, Renee. Create to Learn: Introduction to digital literacy. New Jersey: Wiley Blackwell, 2017.

GONNET, Jacques. Éducation et médias. Paris: PUF, 2001.

GONNET, Jacques. Educação e mídias. São Paulo: Loyola, 2004.

GOVERNO de SP vai distribuir kit escolar para 3,5 milhões de crianças. Jovem Pan, São Paulo-SP, 16 abr. 2020. Disponível em: <https://jovempan.com.br/noticias/brasil/governo-de-sp-vaidistribuir-kit-escolar-para-35-milhoes-de-criancas.html>. Acesso em: 25 abr. 2020.

HENLEY, Jon. How Finland start its fight against fake news in primary schools. The Guardian. Londres-En, 29 jan. 2020. Disponível em: $<$ https://www.theguardian.com/world/2020/jan/28/ fact-from-fiction-finlands-new-lessons-in-combating-fake-news $>$. Acesso em: 25 abr. 2020. 
HOW ARE COUNTRIES ADDRESSING THE COVID-19 CHALLENGES IN EDUCATION? A snapshot of policy measures. World Education Blog UNESCO. Paris, 24 mar. 2020. Disponível em: $<$ https://gemreportunesco.wordpress.com/2020/03/24/how-are-countries-addressing-the-covid-19-challenges-in-education-a-snapshot-of-policy-measures $>$. Acesso em: 15 abr. 2020

KEMP, Simon. Digital 2019: Brazil. Datareportal. 31 jan. 2019. Disponível em: $<$ https://datareportal.com/reports/digital-2019-brazil>. Acesso em: 10 abr. 2020.

LEHER, Roberto; Gonzalez, Jeferson. Ead: As novas tecnologias e a inserção do setor privado na Educação Básica. [Live]. TV unidade classista. Rio de Janeiro, Plataforma YouTube, 16 abr. de 2020. Disponível em: https://www.youtube.com/watch?v=fJcnWtv_d58. Acesso em: 26 abr. 2020.

NÓVOA, António. Conversa com António Nóvoa. A educação em tempos de pandemia (Covid 19 / Coronavirus). [Entrevista concedida a] Gabriel Ferreira. Sindicato dos professores municipais de Novo Hamburgo, Novo Hamburgo, Plataforma YouTube, 8 de abr. de 2020. Disponível em: $<$ https://www.youtube.com/watch?v=FNF7i_DpfIo $>$. Acesso em: 20 abr. 2020.

MARTÍN-BARBERO, Jesus. De los medios a las mediaciones: comunicación, cultura y hegemonía. 4. ed. Bogotá: Convenio Andrés Bello, 1998.

MARTÍN-BARBERO, Jesus. A comunicação na educação. São Paulo: Contexto, 2014.

MASTERMAN, Len. Teaching the media. Londres: Commedia, 1985.

MASTERMAN, Len. Media education in 1990's Europe. Estrasburgo: Councill of Europe, 1994.

MASTERMAN, Len. A scuola di media. Educazione, media e democrazia nell'Europa degli anni '90, Brescia: La Scuola, 1997.

MIRANDA, Lyana Thédiga de; FANTIN, Monica. A perspectiva social das competências midiáticas: reflexões sobre participação e interação das crianças na escola. Revista Lumina, v. 12, n.1, p. 55-67, jan./abr. 2018.

NÓVOA, António. Conversa com António Nóvoa. A educação em tempos de pandemia (Covid 19 / Coronavirus). [Entrevista concedida a] Gabriel Ferreira. Sindicato dos professores municipais de Novo Hamburgo, Novo Hamburgo, Plataforma YouTube, 8 de abr. de 2020. Disponível em: $<$ https://www.youtube.com/watch?v=FNF7i_DpfIo $>$. Acesso em: 20 abr. 2020.

\footnotetext{
plupais 
PESQUISA NACIONAL POR AMOSTRA DE DOMICÍLIOS. Biblioteca IBGE, 2018. Dis-

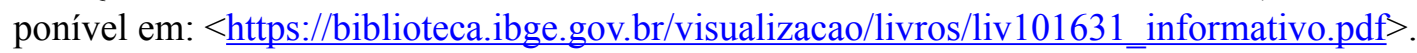
Acesso em: 21 abr. 2020.

PESQUISA SOBRE O USO DAS TECNOLOGIAS DE INFORMAÇÃO E COMUNICAÇÃO NOS DOMICÍLIOS BRASILEIROS: TIC domicílios 2018. [livro eletrônico] / Núcleo de Informação e Coordenação do Ponto BR, [editor]. - São Paulo: Comitê Gestor da Internet no Brasil, 2019. 3.800 Kb; PDF. Disponível em: $<$ https://www.cetic.br/media/docs/publicacoes/2/ 12225320191028tic_dom_2018_livro_eletronico.pdf $>$. Acesso em: 18 abr. 2020.

PREFEITURA do Rio lança whatsapp 1746 para denúncias do DISK aglomeração. Prefeitura do Rio, 15 abr. 2020. Disponível em: $<\underline{\text { http://prefeitura.rio/cidade/prefeitura-do-rio-lanca-what- }}$ sapp-1746-para-denuncias-do-disk-aglomeracao/>. Acesso em: 25 abr. 2020.

RIBEIRO, Ana Melissa Morais. A reforma empresarial da educação e o novo ensino médio. Monografia (Licenciatura em Geografia) - Universidade Federal do Ceará, Fortaleza, 2019.

RIVOLTELLA, Pier Cesare. Media education. Modelli, esperienze, profilo disciplinare. Roma: Carocci, 2001.

RIVOLTELLA, Pier Cesare. Media Education, Fondamenti didattici e prospettive di ricerca. Brescia: La Scuola, 2005.

RIVOLTELLA, Pier Cesare. Screen generation: gli adolescenti e le propettive dell'educazione nell'etá dei media digitali. Milão: Vita e Pensiero, 2006.

RIVOLTELLA, Pier Cesare. Adolescenti e nuovi media: Bisogni sociali, compiti della scuola. Scuola e didattica, v. 17, p. 9-12, 2007.

RIVOLTELLA, Pier Cesare. Fare Didattica com gli EAS. Episodi di Aprendimento Situati. Brescia: La Scuola, 2013.

RIVOLTELLA, Pier Cesare. Neurodidattica: Insegnare al cervello che apprende. Milano: Rafaello Crtina, 2012.

SANTOS, Boa Ventura de. A cruel pedagogia do vírus. Coimbra: Almedina, 2020.

SILVEIRA, Juliano; BRÜGGEMANN, Ângelo Luiz; BIANCHI, Paula. Formação de professores de Educação Física e tecnologias digitais de informação e comunicação (TDIC)/mídia: uma relação possível? Análise das propostas curriculares de universidades federais brasileiras. Motrivivência, Florianópolis, v. 31, n. 57, mar. 2019. 
SILVERSTONE, Roger. Why study the media? Londres: Sage, 1999.

STARTING digital divides in distance learning emerge. UNESCO, Paris, 21 abr. 2020. Disponível em: $<$ https://en.unesco.org/news/startling-digital-divides-distance-learning-emerge $>$. Acesso em: 25 abr. 2020.

Recebido em: 10 de abril de 2020

Inserido em: 20 de maio de 2020

Esta obra está licenciada com uma Licença Creative Commons Atribuição 4.0 Internacional. 